\title{
Single dose of green tea extract decreases lipid digestion and absorption from a test meal in humans*
}

\author{
Jarosław Walkowiak1,2® , Joanna Bajerska², Angelika Kargulewicz³ ${ }^{3}$ Aleksandra Lisowska ${ }^{1}$, \\ Gwidon Siedlerski ${ }^{1}$, Tomasz Szczapa ${ }^{4}$, Natalia Kobelska-Dubiel ${ }^{1}$ and Marian Grzymisławski
}

1Department of Pediatric Gastroenterology \& Metabolic Diseases, Poznan University of Medical Sciences, Poznań, Poland; ${ }^{2}$ Department of Human Nutrition and Hygiene, Poznan University of Life Sciences, Poznań, Poland; ${ }^{3}$ Department of Internal Diseases, Metabolism and Dietetics,

Poznan University of Medical Sciences, Poznań, Poland; “Department of Neonatology, Poznan University of Medical Sciences, Poznań, Poland

Background \& Aims: Green tea is known worldwide for its high content of polyphenolic compounds and multifactorial beneficial effects on human health. The role of green tea as an inhibitor of lipid hydrolysis is widely discussed. The aim of the study was to assess the influence of green tea extract on lipid digestion and absorption. Methods: The study comprised 32 healthy volunteers aged 23 to 30 years with normal exocrine pancreatic function. In all subjects ${ }^{13} \mathrm{C}$-labelled mixed triglyceride breath test was performed twice with and without green tea extract ingestion. Cumulative percentage dose recovery was considered to reflect digestion and absorption of lipids. Values are expressed as medians and 1st-3rd quartile distribution. Results: In all subjects, cumulative percentage dose recovery values were normal in a placebo test $(36.8 \%<30.1-43.3 \%>)$. These results were significantly higher $(p=0.021)$ than those obtained in green tea extract test $(28.8 \%<23.1-37.2 \%>)$. Results of six tests with GTE were abnormal. Conclusions: Single dose of green tea extract taken with a test meal decreases lipid digestion and absorption in humans.

Key words: green tea, digestion, absorption, mixed triglyceride breath test

Received: 03 June, 2013; revised: 29 July, 2013; accepted: 21 August, 2013; available on-line: 29 August, 2013

\section{INTRODUCTION}

Green tea is known worldwide for its high content of polyphenolic compounds and multifactorial beneficial effects on human health. Green tea contains a broad range of catechins: (-)-epicatechin (EC), (-)-epigallocatechin (EGC), (-)-epicatechin gallate (ECG) and (-)-epigallocatechin gallate (EGCG) (Raederstorff et al., 2003; Lee et al., 2009; Lee et al., 2009; Tanaka et al., 2010; Kim et al., 2011). EGCG is the most abundant (50\% of the total amount of catechins in green tea) and possessing the most potent antioxidant activity catechin (Collins et al., 2007; Lee et al., 2009). Green tea and its components show various biological and pharmacological effects like antibacterial, anti-inflammatory and anti-carcinogenic activities (Kim et al., 2009; Shrestha et al., 2009; Huang et al., 2011). Numerous studies conducted in humans have revealed that green tea extract (GTE) decreases weight and body fat gain (Mochizuki \& Hasegawa, 2004). Lee et al. (2009) showed that green tea EGCG inhibits lipid accumulation in cultured adipocytes via stimulation of lipolysis. It is believed that green tea increases energy ex- penditure and for this reason it may have application in a supportive treatment of obesity (Mochizuki \& Hasegawa, 2004; Moon \& Lee, 2007; Bose \& Lambert, 2008; Lee et al., 2009; Lee et al., 2009). The role of green tea as an inhibitor of lipid hydrolysis is widely discussed. However, there are no data evaluating impact of pure GTE on lipid digestion and absorption in humans. The aim of the present study was to assess the influence of GTE on lipid digestion and absorption.

\section{MATERIAL AND METHODS}

The study comprised 32 healthy volunteers aged 23 to 30 years (Table 1) with normal exocrine pancreatic function (fecal elastase-1 concentration $>200 \mu \mathrm{g} / \mathrm{g}$ ) (Walkowiak et al., 2005). Exclusion criteria included: antibiotic therapy within preceding month, acute or chronic diarrhea, celiac disease, pancreatitis, severe systemic disease. In all subjects, ${ }^{13} \mathrm{C}$-labelled mixed triglyceride breath test ${ }^{13} \mathrm{C}$ MTG-BT) was performed twice in a random order, with and without GTE ingestion (GTE and placebo tests). ${ }^{13} \mathrm{C}$ MTG-BT was performed after overnight fasting. Each subject received $150 \mathrm{mg}$ of ${ }^{13} \mathrm{C}$ mixed triglyceride with $12.5 \mathrm{~g}$ butter mixed on a slice of bread and GTE (4 g; EGCG content - $257.6 \mathrm{mg}$, caffeine content $136 \mathrm{mg}$ ) obtained as described below or placebo. Breath samples were collected at baseline (fasting) and at 30,60, 90, 120, 150, 180, 210, 240, 270, 300, 330 and 360 minutes after test meal ingestion. The samples were analyzed with an IRIS ${ }^{13} \mathrm{C}$-Analyser System (Wagner, Bremen, Germany). Cumulative percentage dose recovery (CPDR) was considered to reflect digestion and absorption of lipids, values lower than $13 \%$ were considered to be abnormal (Lisowska et al., 2011).

The green tea extract was prepared according to the method described by Bajerska et al. (2011) from the Japanese Sencha Fukuju Green Tea, which was bought at a specialty store (The House of Tea). The tea leaves (100 g) were ground and then boiled in double-distilled water $(1000 \mathrm{~mL})$, followed by stirring for 15 minutes at $70^{\circ} \mathrm{C}$ (the procedure was repeated 3 times). Collected extracts

e-mail: jarwalk@am.poznan.pl

A poster "Single dose of green tea extract decreases lipid digestion and absorption from a test meal in humans" was presented at XV Congress of Polish Society of Gastroenterology, Kraków, 4-6.10.2012.

Abbreviations: CPDR, cumulative percentage dose recovery; EC, epicatechin; EGC, (-)-epigallocatechin; ECG, (-)-epicatechin gallate; EGCG, (-)-epigallocatechin gallate; GTE, green tea extract; ${ }^{13} \mathrm{C}$ MTG$\mathrm{BT},{ }^{13} \mathrm{C}$-labelled mixed triglyceride breath test 
were filtered through filter paper, centrifuged (at $2700 \times$ $g$, for $15 \mathrm{~min}$ ), frozen and lyophilized under a vacuum (Multi Branch Trade \& Manufacturing Company "Elena," Zelazkow, Poland).

HPLC analyses of green tea catechin contents were performed on a Waters Alliance HPLC System 2695 (Milford, Mass, USA) equipped with an X-Terra RP18 $5 \mu \mathrm{m}$ column (Milford) according to the method described by Andrade et al. (2002) with slight modifications by the authors.

Results are expressed as medians and 1st-3rd quartile distribution. The statistical significance of differences in CPDR between GTE and placebo tests was determined with the use of Wilcoxon-rank test. The level of significance was set at $p<0.05$. Statistical analysis was performed using STATISTICA 8.0. (StatSoft Inc. 2008). The protocol of the investigation was approved by the Bioethical Committee of Poznan University of Medical Sciences, Poland.

\section{RESULTS}

In all subjects, CPDR values were normal in a placebo test $(36.8 \%<30.1-43.3 \%>)$. These results were significantly higher $(p=0.021)$ than those obtained in GTE test $(28.8 \%<23.1-37.2 \%>)$. A tendency towards increasing differences between the two tests was observed throughout whole test, reaching a statistical significance at 300 minutes (Table 2). Interestingly, in six subjects the CPDR values in the test with GTE consumption were abnormal (range 5.8-12.0\%). No correlation was found between the effect of GTE ingestion and demographic data (sex, age, BMI).

\section{DISCUSSION}

In the present study, a single dose of GTE taken with a test meal decreased lipid digestion and absorption. Based on the information that the mean EGCG content of a single cup $(200 \mathrm{~mL})$ of tea prepared with $2 \mathrm{~g}$ of green tea leaves ranges between $4.62 \mathrm{mg}$ and 406.4 mg (Bhagwat et al., 2011), dose of green tea extract (4 g) used in our study was equivalent to intakes at least several cups of green tea and, in some cases, more than 10 cups per day. To the best of our knowledge, this is the first study evaluating the impact of pure GTE on lipid digestion and absorption in humans. Currently, the role of green tea as an inhibitor of lipid hydrolysis is widely discussed. A study conducted on mice provided evidence that EGCG increases fecal excretion of lipids supporting the claim that EGCG decreases lipid digestion and absorption (Raederstorff et al., 2003; Unno et al., 2005; Moon \& Lee, 2007; Bose \& Lambert, 2008; Kim et al., 2011; 2012; Sae-tan et al., 2011). A study on rats with inserted mesenteric lymph cannulas has revealed that green tea inhibits the intestinal absorption of dietary li-

Table 1. Basic epidemiological data of study subjects $(n=32)$.

\begin{tabular}{lll}
\hline Parameter & Range & Median \\
\hline Age (years) & $22-30$ & 24 \\
\hline Height $(\mathrm{cm})$ & $160-195$ & 174 \\
\hline Body weight $(\mathrm{kg})$ & $47.0-94.9$ & 60.0 \\
\hline BMl $\left(\mathrm{kg} / \mathrm{m}^{2}\right)^{*}$ & $18.5-25.0$ & 21.0 \\
\hline
\end{tabular}

*BMI, body mass index pids, including triacylglycerol, cholesterol and lipophylic compounds like $\alpha$-tocopherol (Raederstorff et al., 2003; Unno et al., 2005; Koo \& Noh, 2007; Shrestha et al., 2009; Rains et al., 2011). EGCG has been suggested to regulate various enzymes related to lipid metabolism, such as pancreatic and gastric lipase Juhel et al., 2000; Raederstorff et al., 2003; Koo \& Noh, 2007; Moon \& Lee, 2007; Rains et al., 2011). Some authors attribute the

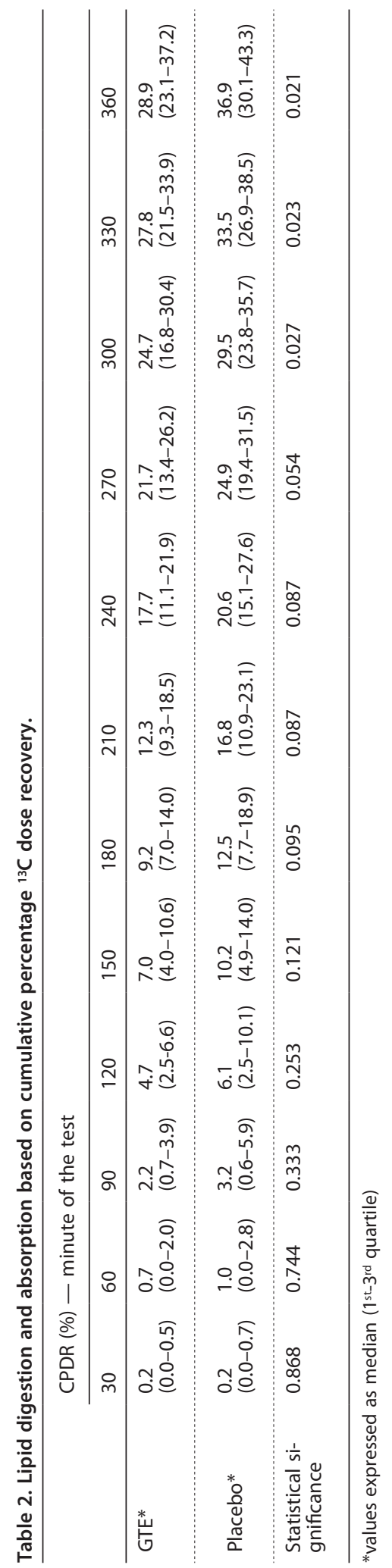


competence to inhibit pancreatic lipase activity in vitro to tea saponins and not catechins (Han et al., 1999). Gondoin et al. (2010) have shown that strictinin (a tea leaf catechin fraction) has the strongest inhibitory effect on pancreatic lipase activity in vitro. In a study conducted on rats, Ikeda et al. (2005) proved that GTE containing $59.6 \mathrm{~g}$ of catechins per $100 \mathrm{~g}$ of dry weight dosedependently inhibits pancreatic lipase activity. In that study rats were cannulated in the thoracic duct. On the other hand, Zhong et al. (2006) provided evidence that a beverage containing $0.1 \mathrm{~g}$ black, $0.1 \mathrm{~g}$ green and $0.1 \mathrm{~g}$ mulberry teas caused malabsorption of carbohydrates but did not affect triacylglycerol absorption as evaluated with the use of ${ }^{13} \mathrm{C}$ MTBT. In contrast to the latter study, we assessed the influence of pure GTE on lipid absorption and digestion. Some authors claim that the inhibition of lipid absorption stems from the EGCG ability to form complexes with lipids and lipolytic enzymes by interfering with emulsification and micellar solubilization of lipids (Lee et al., 2009; Chan et al., 2011; Kim et al., 2012). EGCG may influence the size of lipid droplets and thereby prevent efficient emulsification. It has been shown that a larger fat droplet size and reduced surface area impede fat digestion by digestive enzymes (Unno et al., 2005). The results obtained in the present study support the concept that pure GTE inhibits lipid digestion and absorption. However, the mechanism responsible for this action in humans remains to be elucidated.

\section{CONCLUSIONS}

A single dose of GTE taken with a test meal decreases lipid digestion and absorption.

\section{Acknowledgements}

The research project was supported by University grants Jarosław Walkowiak - Poznan University of Medical Sciences, Joanna Bajerska — Poznan University of Life Sciences).

\section{REFERENCES}

Andrade PB, Mendes G, Falco V, Valentao P, Seabra RM (2008) Preliminary study of flavonols in port wine grape varieties. Food Chem 73: 397-399.

Bajerska J, Wozniewicz M, Jeszka J, Drzymala-Czyz S, Walkowiak J (2011) Green tea aqueous extract reduces visceral fat and decreases protein availability in rats fed with a high-fat diet. Nutr Res 31: 157-164.

Bhagwat S, Haytowitz DB, Holden JM (2011) USDA database for the flavonoid content of selected foods. http://www.ars.usda.gov/ SP2UserFiles/Place/12354500/Data/Flav/Flav_R03.pdf Accessed October 19, 2011

Bose M, Lambert JD (2008) The major green tea polyphenol, (-)-Epigallocatechin-3-Gallate, inhibits obesity, metabolic syndrome and fatty liver disease in high fat fed mice. J Nutr 138: 1677-1683.

Chan CY, Wei L, Castro-Munozledo F, Koo WL (2011) (-)-Epigallocatechin-3-gallate blocks 3T3-L1 adipose conversion by inhibition of cell proliferation and suppression of adipose phenotype expression. Life Sci 89: 779-785.

Collins QF, Liu HY, Pi J, Liu Z, Quon MJ, Cao W (2007) Epigallocatechin-3-gallate (EGCG), a green tea polyphenol, suppresses hepatic gluconeogenesis through 5'-AMP-activated protein kinase. J Biol Chem 282: 30143-30149.

Gondoin A, Grussu D, Stewart D, McDougall GJ (2010) White and green tea polyphenols inhibit pancreatic lipase in vitro. Food Res Int 43: 1537-1544.

Han LK, Takaku T, Li J, Kimura Y, Okuda H (1999) Antiobesity action of oolong tea. Int J Obes Relat Metab Disord 23: 98-105.

Huang J, Frohlich J, Ignaszewski AP (2011) The impact of dietary changes and dietary supplements on lipid profile. Can J Cardiol 27: 488-505.

Ikeda I, Tsuda K, Suzuki Y, Kobayashi M, Unno T, Tomoyori H, Goto H, Kawata Y, Imaizumi K, Nozawa A, Kakuda T (2005) Tea catechins with a galloyl moiety suppress postprandial hypertriacyloglycerolemia by delaying lymphatic transport of dietary fat in rats. $J$ Nutr 135: 155-159.

Juhel C, Armand M, Pafumi Y, Rosier C, Vandermander J, Lairon D (2000) Green tea extract (AR2 $5^{\circledR}$ ) inhibits lipolysis of triglycerides in gastric and duodenal medium in vitro. J Nutr Biochem 11: 45-51.

Kim JH, Jeon SM, Lee MK, Jung UJ, Shin SK, Choi MS (2009) Antilipogenic effect of green tea extract in C57BL/6J-Lep ${ }^{\text {ob/ob }}$ mice. Phytother Res 23: 467-471.

Kim A, Chiu A, Barone MK, Avino D, Wang F, Coleman CI, Phung OJ (2011) Green tea catechins decrease total and low-density lipoprotein cholesterol: A systematic review and meta-analysis. $J \mathrm{Am}$ Diet Assoc 111: 1720-1729.

Kim J, Koo SI, Noh SK (2012) Green tea extract markedly lowers the lymphatic absorption and increases the biliary secretion of ${ }^{14} \mathrm{C}$ benzo[a]pyrene in rats. J Nutr Biochem 23: 1007-1711.

Koo SI, Noh SK (2007) Green tea as inhibitor of the intestinal absorption of lipids: potential mechanism for its lipid-lowering effect. J Nutr Biochem 18: 179-183.

Lee MS, Kim CT, Kim IH, Kim Y. (2009) Inhibitory effects of green tea catechin on the lipid accumulation in 3T3-L1 adipocytes. Phytother Res 23: 1088-1091.

Lee MS, Kim CT, Kim Y (2009) Green tea (-)-epigallocatechin-3-gallate reduces body weight with regulation of multiple genes expression in adipose tissue of diet-induced obese mice. Ann Nutr Metab 54: 151-157.

Lisowska A, Pogorzelski A, Oracz G, Siuda K, Skorupa W, Rachel M, Cofta S, Piorunek T, Walkowiak J (2011) Oral antibiotic therapy improves fat absorption in cystic fibrosis patients with small intestine bacterial overgrowth. I Cyst Fibros. 10: 418-421.

Moon HS, Lee HG (2007) Proposed mechanisms of (-)-epigallocatechin-3-gallate for anti-obesity. Chem Biol Interact 167: 85-98.

Mochizuki M, Hasegawa N (2004) Effects of green tea catechin-induced lipolysis on cytosol glycerol content in differentiated 3T3-L1 cells. Phytother Res 18: 945-946.

Raederstorff DG, Schlachter M, Elste V, Weber P (2003) Effect of EGCG on lipid absorption and plasma lipid levels in rats. J Nutr Biochem 14: 326-332.

Rains TM, Agarwal S, Maki KC (2011) Antiobesity effects of green tea catechins: a mechanistic review. I Nutr Biochem 22: 1-7.

Sae-tan S, Grove KA, Lambert JD (2011) Weight control and prevention of metabolic syndrome by green tea. Pharmacol Res 64: 146-154.

Shrestha S, Ehlers S J, Lee JY, Fernandez ML, Koo SI (2009) Dietary green tea extract lowers plasma and hepatic triglycerides and decreases the expression of sterol regulatory element-binding protein 1-c mRNA and its responsive genes in fructose-fed, ovariectomized rats. I Nutr 139: 640-645.

Tanaka K, Tamaru S, Nishizono S, Miyata Y, Tamaya K, Matsui T, Tanaka T, Echizen Y, Ikeda I. (2010) Hypotriacylglycerolemic and antiobesity properties of a new fermented tea product obtained by tea-rolling processing of third-cropp green tea (Camellia sinensis) leaves and loquat (Eriobotrya japonica) leaves. Biosci Biotechnol Biochem 74: 1606-1612.

Unno T, Tago M, Suzuki Y, Nozawa A, Sagesaka YM, Kakuda T, Egawa K, Kondo K (2005) Effect of tea catechins on postprandial plasma lipid responses in human subjects. Br J Nutr 93: 543-547.

Walkowiak J, Nousia-Arvanitakis S, Henker J, Stern M, Sinaasappel M, Dodge JA (2005) Indirect pancreatic function tests in children. J Pediatr Gastroenterol Nutr 40: 107-114.

Zhong L, Furne J K, Levitt MD (2006) An extract of black, green and mulberry teas causes malabsorption of carbohydrate but not of triacyloglycerol in healthy volunteers. Am J Clin Nutr 84: 551-555. 